\title{
ARTIGO
}

\section{ESCOLHER SER PROFESSOR E REALIZAR-SE NA PROFISSÃO: DILEMAS DO TRABALHO DOCENTE}

Choose to be a teacher and perform in the profession: dilemma of the teaching work

Elegir ser un maestro y llevar a cabo en la profesión: dilema del trabajo docente

Arinalda Silva Locatelli

Universidade Federal do Tocantins - Brasil

Cleomar Locatelli

Universidade Federal do Tocantins - Brasil

\section{Resumo}

A literatura sobre a profissão docente traz à tona a complexa temática referente ao seu processo de profissionalização. O presente texto traz reflexões sobre a profissão docente na América Latina articuladas com uma pesquisa efetivada em 2012 com professores (as) da rede municipal de ensino da cidade de Tocantinópolis - TO, objetivando perceber similitudes e diferenças entre um contexto micro e o panorama mundial em relação a escolha e satisfação na profisssão. A literatura de referência lembra que a profissão em pauta tem um viés político, logo, a construção de saída para os dilemas inerentes ao cotidiano docente está na construção coletiva de alternativas, que passa pela sua organização enquanto categoria profissional.

Palavras-chave: Docência. Realização profissional. Trabalho docente.

\begin{abstract}
The literature on the teaching profession brings out the complex theme related to its professionalization process. This paper reflects on the teaching profession in Latin America hinged to a survey carried out in 2012 with teachers of municipal schools in the city of Tocantinópolis - TO, aiming to understand similarities and differences between a micro context and the global picture in relation to choice and satisfaction in the profession. The reference literature points out that the profession in question has a political bias, so the output of construction for the dilemmas inherent in everyday teaching is the collective construction of alternatives, what goes through your organization as a professional category.
\end{abstract}

Keywords: Teaching. Professional achievement. Teaching work

\section{Resumen}

La literatura sobre la profesión docente lleva a cabo el complejo tema relacionado con su proceso de profesionalización. En este trabajo se refleja en la profesión docente en América 
Latina articulada a una encuesta realizada en 2012 con los maestros (as) de las escuelas municipales de la ciudad de Tocantinópolis - A, con el objetivo de comprender las similitudes y diferencias entre un contexto micro y en el escenario mundial respecto a la elección y la satisfacción en la profesión. La literatura de referencia señala que la profesión de que se trate tiene un sesgo político, por lo que la producción de la construcción de los dilemas inherentes a la enseñanza diaria es la construcción colectiva de alternativas, lo que pasa por su organización como una categoría profesional.

Palabras clave: Enseñanza. Logro profesional. Trabajo de Enseñanza.

\section{Introdução}

O exercício da profissão docente na América Latina, ao longo de sua trajetória histórica e social é demarcado pela heterogeneidade e subjetividade dos profissionais que exercem o magistério. Ancorado em uma pesquisa que desenvolveu em quatro países latinos (Brasil, Uruguai, Argentina e Peru) Fanfani (2005), considera que a unanimidade não é uma regra no mundo da docência, mas é possível perceber algumas similaridades no contexto latino-americano. Trata-se de uma profissão onde numericamente predominam as mulheres, especialmente no nível primário; permite uma inserção mais rápida no mercado de trabalho, em alguns casos antes mesmo de concluir a formação inicial; compõem-se de profissionais que na sua maioria a exercem como única atividade remunerada e que diferentemente do que se poderia pensar não desejam dedicar-se a outra profissão; constituindo ainda, especialmente no caso do Brasil, um mecanismo de mobilidade social.

Ainda segundo Fanfani (2005), mesmo que o contexto evidencie questões de desigualdades sociais, como por exemplo, o fato da maioria dos professores não terem acesso a bens culturais, observa-se entre os docentes um grau de satisfação com a profissão em si. Os pontos de insatisfação apontam para as condições salariais e de trabalho, que nos encaminha para os problemas relacionados à intensificação e precarização do trabalho docente, situações que aliadas à perda do reconhecimento social tem sido motivo de desestímulo à profissão. Esses e outros pontos representam conteúdos necessários nas agendas de discussões das políticas públicas voltadas para profissão docente, pois significam, em sua maioria, desafios a serem superados rumo a uma real valorização do trabalho docente.

Depreende-se que as reformas dos anos de 1990 buscaram transferir para os sistemas educativos os novos modelos de organização empresarial, que se implementaram por meio da: descentralização, "autonomia" das instituições, o diretor como "gerente"/gestor, regulação e 
accountability dos docentes. Que têm sido sentidas no cotidiano escolar por meio de programas que são, em geral, um conjunto de aferição de resultados, definição de mínimos curriculares e níveis de aprendizagem, avaliação da qualidade profissional dos docentes e pagamento por rendimento, conforme pontuam Tello e Almeida (2014).

O presente trabalho visa articular algumas das reflexões atuais sobre a "Profissão docente na América Latina" com uma pesquisa efetivada em 2012 com professores (as) da rede municipal de ensino da cidade de Tocantinópolis - TO, objetivando perceber similitudes e diferenças entre um contexto micro e o panorama mundial em relação à escolha e satisfação na profissão.

\section{Alguns pontos de reflexão sobre a profissão docente na América Latina: a interseção formação e trabalho}

Uma visão panorâmica da docência na América Latina evidencia que as necessidades educativas atuais não são as mesmas que marcaram a origem da profissão docente no período de estruturação dos Estados Nacionais. Estas mudanças são sentidas, por exemplo, na relação com as famílias dos discentes e com as novas tecnologias de informação. Em relação às famílias, a sua nova configuração social exige dos docentes uma revisão do próprio conceito de família e o cumprimento de tarefas que excedem o estritamente pedagógico. Quanto às novas tecnologias, sua inserção no cotidiano docente, pressupõe o desenvolvimento de novas habilidades e saberes, que acabam recaindo nas discussões sobre o currículo das formações docentes.

Cabe ressaltar ainda que, ao se falar de profissão docente é importante fazer referência ao processo de formação de seus integrantes, que embora tenha completado 180 anos no Brasil, demarcados pela criação, em 1835, da primeira Escola Normal em Niterói - RJ, ainda é uma história pouco conhecida pelos próprios profissionais do magistério.

Em relação à formação denominada inicial, resguardadas as especificidades de cada país, é consensual a dificuldade da articulação com a prática. No caso do Brasil, vemos esta situação representada no dilema entre os dois modelos de formação que perpassa toda a história da profissão docente, conforme analisa Saviani (2009). De um lado, tem-se a ênfase na cultura geral e conhecimentos disciplinares, presentes na formação universitária, e do outro a prevalência das questões pedagógico-didáticas, que esteve em pauta nas Escolas Normais. Percebe-se a partir do autor supracitado e de Maldonado (2010) que o caminho para superação deste dilema está na constituição de currículos de formação que indissociem as 
duas vertentes. Onde se valorize, no caso dos professores já em serviço, os conhecimentos que possuem e no caso daqueles que ingressarão na docência, que as situações escolares se transformem em "questões analíticas" que propiciem a unidade teoria e prática.

Outro ponto que chama atenção quando se trata de formação inicial, diz respeito a instituição responsável por executar a formação: Institutos ou Universidades? É importante notar que este dilema tem possibilitado a proliferação de diversas instituições de formação, muitas de caráter privado, algumas com objetivo de massificar certificados ao invés de formar bons profissionais, atuando sem bibliotecas, laboratórios, etc.

Em se tratando da formação continuada, na maioria dos casos as propostas têm se resumido a realização de cursos de curta duração (oficinas, seminários) que não assinalam uma expectativa de continuidade. Ou tem significado investimento em livro didático, com base na lógica custo-benefício, sintetizando a formação docente no "bom manejo" desse recurso (TORRES, 2000). Uma possibilidade, em expansão, apresentada pela autora rumo a mudanças significativas, embora ainda não represente uma ação efetiva de política pública, diz respeito a realização de experiências conjuntas, seja entre professores da mesma escola, entre escolas dentro do país ou no intercâmbio com outros países. Entendemos que uma destas perspectivas diz respeito às comunidades de práticas, definida por Ávalos (2011, p. 239) como "grupo de pessoas que compartilham uma preocupação ou paixão por algo que realizam e que na medida em que interagem de forma regular aprendem como melhorar esta atividade". O diferencial dessa ótica está no conceito de "liderança distribuída", onde todos os membros do grupo devem liderar em algum momento, pressupondo o trânsito de uma participação periférica para uma participação total nos encaminhamentos das decisões. (ÁVALOS, 2011).

É importante mencionar ainda um ponto analisado por Torres (2000) quando cita que persiste a ideia de que só quem tem que aprender são os docentes, porém os problemas da educação podem residir no desenho das políticas e dos programas e não exatamente na execução delas. Tal perspectiva é reiterada por Vezub (2009) quando afirma que o desafio está em construir ações, pensamentos e produções que atendem as necessidades e especificidades da categoria docente e não as urgências das políticas educativas atuais. Assim, os altos níveis de direção e administração também deveriam passar por formações e não só o professorado.

Neste intuito, conforme assinalam Vaillant (2013) e Torres (2000), uma política pública de qualidade deve vincular-se a atratividade pela profissão e a garantia da 
permanência dos docentes nela, especialmente quando se trata do trabalho em contextos com maiores dificuldades socioeconômicas e geográficas, como por exemplo, o meio rural e as áreas indígenas.

\section{A prática docente: entre a escolha e a realização profissional}

A literatura sobre a profissão docente traz à tona a complexa temática referente ao seu processo de profissionalização. A este respeito Enguita (2001, p. 54) constata que: "temos um grupo de professores, com origem e características formais de uma profissão burocrática, porém com ideal coletivo e a prática informal de uma profissão liberal”. Reiterando a questão, Ludke e Boing aludem que (2004, p.1161) "há consensos entre os especialistas ao conceituar profissões, mas há certos traços incompatíveis ao se tentar aplicar esse conceito ao magistério". O dilema enunciado liga-se a duas questões que se complementam e possuem vários desdobramentos: primeiro, a natureza do trabalho docente (vocação/missão ou serviço público estatal) e a segunda, as mudanças no cenário socioeconômico da América Latina que vem afetando as relações de trabalho e tem se configurado na precarização do trabalho docente.

Quanto à primeira questão, Ludke e Boing (2004) consideram que a identidade profissional docente está atrelada a instituição escolar, ou seja, a escola é o lugar onde, por meio da prática, o repertório pedagógico necessário ao exercício da profissão, a identidade se consolida. Tal afirmação, deixa claro sua diferença com as profissões de caráter liberal, que não se prendem às instituições, mas por outro lado, reforça seu viés burocrático, a partir de sua base estatal. Todavia, para Enguita (2001), nem a perspectiva liberal, nem a burocrática adequam-se ao que a educação pública deveria ser. O referido autor chama atenção para a necessidade da construção de um modelo profissional democrático que estaria ligado ao compromisso com os fins da educação enquanto serviço "para" e "com" o público, visando assim um trabalho de fato integrado entre escola e comunidade.

Relativo à segunda questão, Fanfani (2007), Ludke e Boing (2004) concordam que a sociedade tende a ver o professor como um salvador da pátria e esperam mais do que a escola é capaz de produzir, especialmente se considerarmos que as múltiplas funções que lhes são atribuídas não são seguidas das condições necessárias para sua efetivação. Instaura-se assim um forte sentimento de lacuna entre o ideal e a realidade do ofício a ser desenvolvido. O que acaba ocasionando situações ambivalentes em que ao mesmo tempo em que se sente gratificado pelo trabalho que desenvolve, vivencia situações ligadas ao mal-estar docente. 
Soma-se a isso, a transformação da noção de trabalho, que passa de um contexto onde se tinha uma definição explicita e prescritiva das tarefas a serem desenvolvidas, para uma realidade de obrigações implícitas, de investimento pessoal, cercada de incertezas e dependente da criatividade individual e coletiva. O professor passa daquele que ensina para aquele que facilita a aprendizagem. Emerge ainda neste cenário a noção de empregabilidade, que repassa para o indivíduo a responsabilidade de se manter no mercado de trabalho.

Tendo em vista estas e outras questões constitutivas do cenário docente que tem resultado na pouca atratividade pela carreira ou ainda no abandono da profissão, procuramos tecer algumas considerações com base em uma pesquisa desenvolvida com professoras ${ }^{1}$ da rede municipal de ensino de Tocantinópolis no Norte do estado do Tocantins.

\section{O que dizem as professoras}

A pesquisa mencionada refere-se a um estudo de caso na rede municipal de ensino, da cidade de Tocantinópolis, que possui um pouco mais de 23 mil habitantes, segundo dados do IBGE (2010) e fica localizada ao norte do estado do Tocantins, numa região denominada Bico do Papagaio ${ }^{2}$. A referida rede é formada por um quantitativo de 15 escolas, sendo 09 localizadas na área urbana e 06 na área rural. Em relação ao atendimento, conforme dados do último Censo Escolar, a rede municipal de ensino matriculou 445 alunos na creche, 604 na pré-escola e 2.392 no ensino fundamental anos iniciais (INEP, 2015).

No conjunto da pesquisa buscou-se reunir informações sobre o perfil socioeconômico das professoras, considerando seu acesso a bens materiais e culturais, sua satisfação com a profissão e com a sua qualidade de vida. O objetivo do levantamento de dados foi possibilitar uma análise das condições sociais e econômicas destas profissionais, relacionando sua vida (condições concretas) à sua tarefa como docente, cada vez menos atraente para os jovens e mais complexa diante do avanço da tecnologia, da abrangência das redes de comunicação e das diversas formas de produção e circulação do conhecimento. O principal instrumento para coleta das informações foi a aplicação de questionário, composto de questões abertas e fechadas, junto as professoras da rede de ensino do referido município, durante os meses de maio e junho de 2012. Ao todo foram aplicados 63 questionários o que representou, em

\footnotetext{
${ }^{1}$ Passaremos a usar o termo somente no feminino em virtude dos respondentes da pesquisa serem todas do sexo feminino, fator característico da profissão, especialmente nos níveis da Educação Infantil e Ensino Fundamental.

2 Tal denominação faz referência ao desenho geográfico que delimita as fronteiras do estado por dois importantes rios do país: Tocantins e Araguaia.
} 
média, uma amostra de 41,44\%, num universo de 152 professoras da rede municipal de ensino.

Vale ressaltar que embora a pesquisa realizada tenha compreendido três dimensões: bens materiais, cultura e lazer e subjetividade docente. Destacamos aqui somente a última dimensão, tangente às respostas das professoras sobre duas questões que buscam revelar aspectos da subjetividade docente: se escolheu ou não ser professora e se estaria realizada com sua prática docente. As duas primeiras dimensões encontram-se discutidas em outro artigo.

\section{a) A escolha da profissão}

A primeira questão procurou saber se as professoras escolheram ou não exercer a profissão docente. Nas respostas constatou-se que 58,7\% declaram que sim, 39,6\% responderam que não e 1,6\% deixaram em branco (ver gráfico 1), verificando-se, portanto, que mais da metade escolheu ser professora. Dado este que se assemelha ao estudo realizado por Souto e Paiva (2013) a respeito dos alunos egressos do curso de matemática em São João Del-Rei, onde de 94 alunos, 53\% fizeram a opção pela licenciatura, movidos pelo desejo de ser professor.

Quando solicitadas a justificar sua opção, as professoras que declararam terem escolhido a profissão apresentaram as seguintes justificativas: (10) por falta de outras opções na cidade; (08) por gostar de ensinar; (05) por identificação com a profissão; (02) por compromisso social e (04) pelo fato da educação ser um campo com mais oportunidade de trabalho.

Cabe destacar que das cinco justificativas apresentadas, com exceção da primeira, três corroboram com a escolha do magistério ligada ao campo dos valores altruístas e da realização pessoal, conforme constata Tartuce et. al. (2010) e a última confirma informações já apresentadas por Fanfani (2005) ao mencionar que, no caso do magistério, o acesso ao primeiro emprego se dá antes da obtenção do título ou nos primeiros seis meses após recebêlo. Na realidade brasileira, segundo o autor, isto representa $52,2 \%$ dos casos.

Tal fato representa um diferencial para os filhos da classe trabalhadora que em sua maioria precisam conciliar formação e trabalho. Inclusive no lócus de nossa pesquisa, onde a indústria e a agricultura geram poucos empregos e o comércio não tem apresentado qualquer desenvolvimento significativo nos últimos anos, o mercado de trabalho ligado a educação se 
torna um atrativo pelo número de vagas que oferece. Em relação as entrevistadas que declararam não ter escolhido a profissão as justificativas giram em torno dos seguintes motivos: (13) falta de opção ou oportunidade para fazer outro curso; (04) por maior possibilidade de emprego na educação; (03) está na sala de aula por acaso; (02) por vontade da família. As demais não justificaram a resposta.

Observa-se que duas justificativas aparecem nos dois casos, ou seja, tanto para aqueles que declararam terem escolhido ser professor como para os que não escolheram: "falta de opção" e "maior possibilidade de emprego". Cabe destacar também que a influência da família na opção profissional, neste caso, não se apresenta como relevante, o que ratifica a ideia de que a docência como herança familiar é um fenômeno que tende a diminuir com o tempo. (FANFANI, 2005)

\section{Gráfico 1 - Se escolheu ou não ser professora}

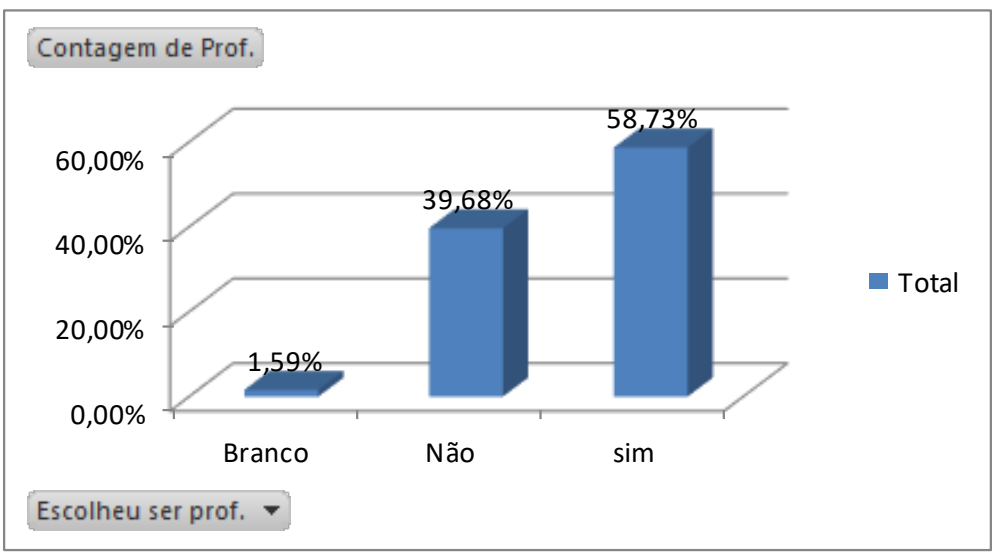

Fonte: Aplicação de questionários (2012)

\section{b) Definição em relação à prática educativa}

A segunda questão indagou a respeito do sentimento de realização na profissão que exerce. Sobre este aspecto as respostas foram: $15,8 \%$ se sentem realizadas, $71,4 \%$ se dizem realizadas em parte e 12,7\% não se sentem realizadas, conforme gráfico 2 .

É interessante observar que, se olharmos de forma isolada o percentual das que se declararam realizadas, os dados coletados apresentam certa diferenciação, tanto em relação à pesquisa de Fanfani (2005), onde 79,3\% dos professores brasileiros se declararam satisfeitos com a atividade docente em si, quanto da pesquisa desenvolvida pelo Grupo de Estudos sobre 
Política Educacional e Trabalho Docente - GESTRADO (2010) ${ }^{3}$, onde 50\% dos entrevistados sentem-se satisfeitos com a profissão. Todavia, se agregarmos a categoria das realizadas com as realizadas em parte podemos inferir que temos uma maioria de professoras relativamente satisfeitas com a profissão.

Quando solicitado que justificassem sua opção, a maioria não respondeu. Apenas três (03) das professoras que se sentem realizadas apresentaram os seguintes argumentos: a identidade com a educação; aprendeu a gostar da profissão e a boa relação no ambiente de trabalho.

Das professoras que se declaram não realizadas, seis (06) justificaram sua afirmação da seguinte forma: muitas exigências e poucas condições; poucos investimentos na área; baixa remuneração; e condições de trabalho. Sendo que o motivo "baixa remuneração" foi apresentado por duas respondentes.

O grupo que mais justificou sua resposta foi das professoras que se declararam realizadas em parte, os motivos apresentados foram: (12) muita cobrança e pouca condição de trabalho; (11) baixa remuneração; (05) precisa mais conhecimento diante dos desafios; (03) indisciplina dos alunos e omissão da família; (03) falta de reconhecimento profissional; (01) o ambiente de trabalho é hostil e (01) não teve oportunidade de fazer outra coisa.

Colocadas em ordem de frequência, constatamos que especialmente as duas primeiras justificativas, para a realização em parte, estão ligadas às questões das condições de desenvolvimento do trabalho e que se fazem presente historicamente nas pautas de reivindicações da categoria no sentido de valorização da profissão. Outrossim, eles aparecem também na justificativa das professoras que não se sentem realizadas na profissão, indicando, salve engano, os fatores determinantes da resposta dada.

Sobre esta temática, Pinto (2009) explica que o Brasil pouco avançou de 1827 até os tempos atuais em termo de valorização profissional, especialmente no que diz respeito a questão salarial, seja em relação a pouca diferença que há entre os valores iniciais e finais na carreira do magistério, ou sobre a perspectiva da remuneração de um professor em comparação com profissionais de outra profissão. Para esse autor, a falta de remuneração adequada é um dos principais desafios da educação brasileira ao longo de sua história, e em

\footnotetext{
${ }^{3}$ A pesquisa foi realizada nos estados do Espírito Santo, Goiás, Minas Gerais, Pará, Paraná, Rio Grande do Norte e Santa Catarina, no período de setembro a dezembro de 2009. Sendo entrevistados 8.795 sujeitos docentes da Educação Básica, desse total, 1.838 eram sujeitos docentes da Educação Infantil. E teve como objetivo analisar o trabalho docente nas suas dimensões constitutivas, identificando seus atores, o que fazem e em que condições se realiza o trabalho nas escolas de Educação Básica da rede pública e conveniada tendo como finalidade subsidiar a elaboração de políticas públicas no Brasil. (GESTRADO, 2010)
} 
sua opinião, a saída para tornar a carreira docente mais atrativa aos jovens do ensino médio passa necessariamente pela questão salarial, haja vista ser esta uma variável fundamental no momento de escolha da profissão.

Cabe lembrar que este é um dos desafios que figuram nas metas a serem alcançadas pelo atual Plano Nacional de Educação (PNE), Lei $n^{\circ} 13.005$, aprovada em 25 de junho de 2014. Conforme podemos observar na redação de sua Meta 17: "valorizar os(as) profissionais do magistério das redes públicas de educação básica de forma a equiparar seu rendimento médio ao dos(as) demais profissionais com escolaridade equivalente, até o final do sexto ano de vigência deste PNE.” (BRASIL, 2014)

Vale ressaltar que, justificativas semelhantes as expressas anteriormente já haviam sido constatadas em pesquisa feita por Penin (1985) referente a questão da satisfação ou insatisfação do professor no trabalho. No estudo realizado a autora defendeu a tese que este assunto deveria passar por uma reorientação teórica, devendo ser compreendido como uma questão pública e não como dependente das idiossincrasias individuais. Suas conclusões enunciam que,

\begin{abstract}
A compreensão tradicional do fenômeno tendia a situar a satisfação/insatisfação no trabalho na esfera privada, encerrando-a no interior do indivíduo. É uma compreensão 'psicologizante', concebendo, quando muito, que se trata de 'efeitos' da ordem social ao nível individual. [...]. As manifestações de satisfação/insatisfação encontradas, e especialmente, as representações dos professores sobre tais manifestações, indicam estrita relação entre estas e algumas características das condições objetivas de trabalho, assim como, da ordem social vigente. Ou seja, os dados [...] sugerem que o potencial de satisfação/insatisfação de um indivíduo no trabalho não depende essencialmente do indivíduo, mas predominantemente, das condições objetivas sociais e históricas nas quais o trabalho se desenvolve (PENIN, 1985, p. 169)
\end{abstract}

Em nossa opinião, embora tenhamos uma diferença temporal significativa, há similaridades entre a pesquisa da autora acima citada e os dados que coletamos, evidenciando assim que este é um assunto ainda em voga, pois a literatura a respeito da profissão docente demonstra que há uma tendência crescente de controle sobre o fazer docente, onde prevalece a racionalidade técnica/instrumental nos modelos de formação, preconizadas pelas reformas dos anos de 1990 quando entrou em cena a noção de competência, que cada vez mais focaliza no indivíduo a responsabilidade pelos resultados de seu trabalho. A exemplo disto, temos os programas de avaliação docente desenvolvidos no México, na Colômbia, no Chile, no Peru e no Equador (TELLO; ALMEIDA, 2014). 


\section{Gráfico 2 - Como as professoras se definem quanto à prática educativa}

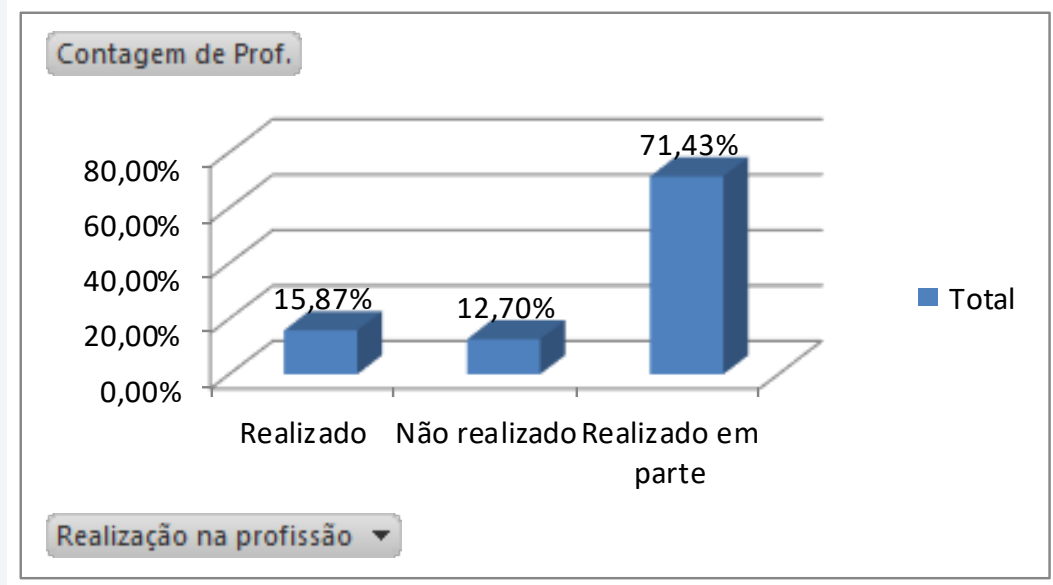

Fonte: Aplicação de questionários (2012)

Ainda no tocante a este aspecto, buscamos perceber se quem escolheu ser professora se sentia mais realizada do que quem não havia escolhido a profissão. Percebemos então que entre aquelas que declararam terem escolhido ser professora: $21,6 \%$ sentiam-se realizados na profissão; $8,1 \%$ sentiam-se não realizados e 70,2\% sentiam-se realizados em parte, conforme gráfico 3.

\section{Gráfico 3 - Sobre a realização das professoras que disseram ter escolhido a profissão}

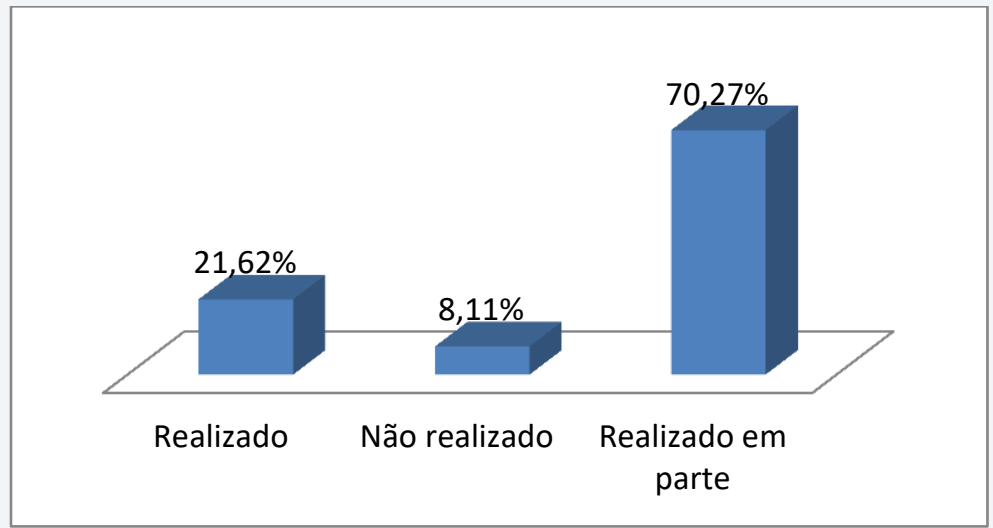

Fonte: Aplicação de questionários (2012)

Entre as professoras que afirmaram não terem escolhido a profissão, percebe-se que: $8 \%$ sentiam-se realizadas; $20 \%$ sentiam-se não realizadas e $72 \%$ sentiam-se realizadas em parte, conforme gráfico 4. 


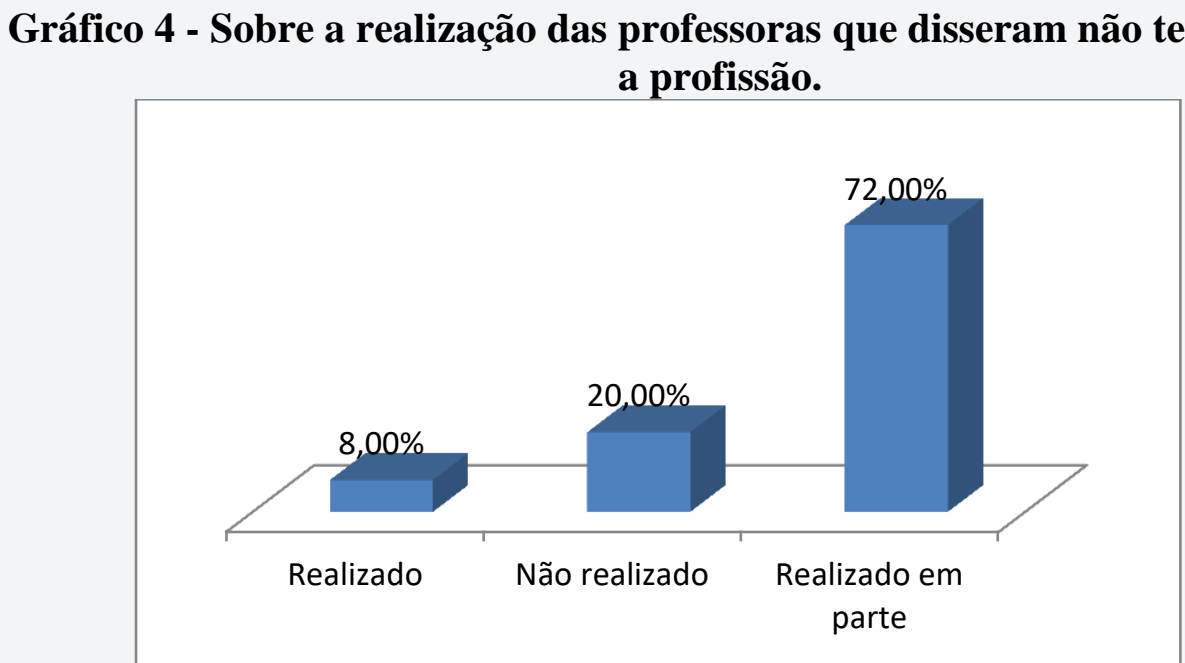

Fonte: Aplicação de questionários (2012)

Os dados demonstram que existe uma significativa diferença no grau de realização e de não realização entre quem escolheu ser professora e quem não escolheu. Mostrando que quem escolheu ser professora tende a sentir-se mais realizada, mesmo diante dos mesmos desafios enfrentados por todos, por conseguinte quem não queria ser professora se sente menos realizada na profissão que exerce. Por outro lado, os índices revelam que este fato não ocorre entre quem respondeu que está parcialmente realizada, sinalizando para uma ínfima diferença nos percentuais.

Arriscamo-nos a dizer que esta constatação pode simbolizar uma confluência com o novo conceito de vocação apresentado nos textos, indicando não um "dom”, "sacrifício" ou "algo inato", mas sim um compromisso, respeito e cuidado com o outro. Fazendo parte da identidade social (ethos) da profissão como afirma Fanfani (2007) e integra as características da profissionalização, segundo Ludke e Boing (2004).

\section{Considerações finais}

A partir das reflexões feitas, mesmo ciente do não esgotamento das possibilidades de análises, consideramos que é possível mencionar, à guisa de conclusão, as seguintes considerações.

Em primeiro lugar, mesmo diante da complexidade que é o exercício da docência, a sua escolha ainda é um atrativo para aqueles provenientes da classe trabalhadora e em muitos casos continua a representar um fator de mobilidade social, pois é uma profissão que permite uma inserção mais rápida no mercado de trabalho, muitas vezes ainda sem ter concluído a formação inicial. 
Em segundo lugar, a satisfação ou insatisfação profissional envolve inúmeras questões, referente a fatores internos e externos à escola, de ordem social, econômica e cultural, que se referem diretamente a efetiva atuação no ambiente de trabalho e suas consequências. Desta forma, não é um assunto de cunho exclusivamente individual ou subjetivo. Todavia, observa-se que a responsabilização do próprio trabalhador pela sua insatisfação se torna conveniente no sentido de camuflar as condições de trabalho e desvalorização profissional dos professores. Neste sentido, torna-se pertinente a afirmativa de Antunes $(2004, p .8)$,

Se por um lado, podemos considerar o trabalho como um momento fundante da vida humana, ponto de partida do processo de humanização, por outro lado, a sociedade capitalista o transforma em trabalho assalariado, alienado, fetichizado.

Em terceiro lugar, é perceptível uma acentuação dos desencantos com a profissão, que tem sido causa de índices de adoecimentos e absenteísmos docentes ou mesmo do abandono da profissão, colocando em tela um contexto, de uma crescente precarização do trabalho docente e de uma crise na sua identidade.

Entretanto, diante da realidade que hora se apresenta, os autores estudados nos lembram que a profissão em pauta tem um viés político e ideológico, logo uma saída para seus desafios passa pela construção coletiva de alternativas, que necessita de sua organização enquanto categorial profissional. A este respeito, no cenário brasileiro, atualmente assinalado pela implantação das metas do novo PNE, faz-se necessário uma ampla mobilização dos diversos atores sociais no sentido de avaliar e acompanhar seu processo de execução. Para tanto, é importante um aprofundamento constante dos conhecimentos acerca das características, especificidades e dilemas da referida profissão no cenário latino-americano, percebendo-os como um movimento dinâmico e complexo.

\section{Referências}

ANTUNES, Ricardo (org.) A dialética do trabalho: escritos de Marx e Engels. São Paulo: Expressão Popular, 2004.

ÁVALOS, Beatrice. El liderazgo docente en comunidades de práctica. Educar, v. 47, n. 2, p. 237- 252, 2011.

BRASIL. Lei no 13.005, de 25 de junho de 2014. Aprova o Plano Nacional de Educação PNE e dá outras providências. Diário Oficial da União, Brasília, DF, 26 jun. 2014.

ENGUITA, Mariano Fernández. A la busca de un modelo profesional para la docencia: 
¿liberal, burocrático o democrático? Revista Ibero-americana de Educación, n. 25, p. 43 64, ene./abr. 2001.

EVANGELISTA, Olinda; SHIROMA, Eneida Oto. Professor: protagonista e obstáculo da reforma. Educação e Pesquisa, v. 33, n. 3, p. 531-541, set./dez. 2007.

FANFANI, Emílio Tenti. Consideraciones sociológicas sobre profesionalización docente. Educação \& Sociedade, vol. 28, n. 99, p. 335-353, maio/ago. 2007.

FANFANI, Emílio Tenti. La condición docente: datos para el análises comparado: Argentina, Brasil, Perú y Uruguay. Buenos Aires: Siglo Vientiuno, 2005.

FELDFELBER, Myriam. La regulación de la formación y el trabajo docente: un análisis crítico de la "agenda educativa" en América Latina. Educação e Sociedade, v. 28, n. 99, p. 444-465, maio/ago. 2007.

INSTITUTO BRASILEIRO DE GEOGRAFIA E ESTATÍSTICA. Censo demográfico 2010. Disponível em: http://www.ibge.gov.br/cidadesat/default.php. Acesso em: novembro de 2015. LUDKE, Menga; BOING, Luiz Alberto. Caminhos da profissão e da profissionalidade docentes. Educação \& Sociedade, vol. 25, n. 89, p. 1159-1180, set./dez. 2004.

MALDONADO, Ruth Mercado. Un debate actual sobre la formación inicial de docentes en México. Psicologia Escolar e Educacional, v. 14, n. 1, p. 149-157, jan./jun. 2010.

TARTUCE, Gisela Lobo et. al. Alunos do ensino médio e atratividade da carreira docente no Brasil. Cadernos de Pesquisa, v. 40, n. 140, p. 445-477, maio/ago. 2010.

OLIVEIRA, Dalila Andrade. Política educacional e a re-estruturação do trabalho docente: reflexões sobre o contexto latino-americano. Educação e Sociedade, vol. 28, n. 99, p. 355375, maio/ago. 2007.

OLIVEIRA, Dalila Andrade; VIEIRA, Lívia Maria Fraga. Trabalho docente na educação básica no Brasil: sinopse do survey nacional [2009]. Belo Horizonte: GESTRADO/UFMG, 2010.

PENIN, Sonia. T. de S. A questão pública a satisfação/insatisfação do professor no trabalho. Revista Faculdade de Educação. São Paulo, v.11(1/2), pág. 149-172, jan./dez., 1985.

PINTO, José Marcelino Rezende. Remuneração adequada do professor: Desafio à educação brasileira. Revista Retratos da Escola, v. 3, n. 4, p. 51-67, jan./jun. 2009.

SAVIANI, Demerval. Formação de professores: aspectos históricos e teóricos do problema no contexto brasileiro. Revista Brasileira de Educação, v. 14, n. 40, p. 143-155, jan./abr. 2009.

SOUTO, Romélia Mara Alves; PAIVA, Paulo Henrique Apipe Avelar de. A pouca atratividade da carreira docente: um estudo sobre o exercício da profissão entre egressos de uma Licenciatura em Matemática. Pro-Posições, v. 24, n. 1, p. 201-224, jan./abr. 2013.

TARTUCE, Gisela Lobo et. al. Alunos do e nsino médio e atratividade da carreira docente no Brasil. Cadernos de Pesquisa, v. 40, n. 140, p. 445-477, maio/ago. 2010. 
TELLO, César; ALMEIDA, Maria de Lourdes Pinto de. Políticas educativas e profissionalização docente na América Latina. Revista Lusófona de Educação, n. 26, p. 161174, 2014.

TORRES, Rosa María. Balance y perspectiva de la formación docente en América Latina. Ciencia y Sociedade, v. XXV, n. 3, p. 368-394, jul.-sept. 2000.

VAILLANT, Denise. Formación inicial del profesorado en América Latina: dilemas centrales y perspectivas. Revista Española de Educación Comparada, n. 22, p. 185-206, 2013.

VEZUB, Lea Fernanda. Notas para pensar una genealogía de la formación permanente del profesorado en Argentina. Revista Mexicana de Investigación Educativa, v. 14, n. 42, p. 911-937, jul./sept. 2009.

Doutoranda Arinalda Silva Locatelli Universidade Federal do Tocantins - Brasil

Campus de Tocantinópolis - TO Membro do Grupo de Estudos sobre Política Educacional e Trabalho Docente (GESTRADO/UFMG) Bolsista do CNPq E-mail: naldalli@uft.edu.br

Dr. Cleomar Locatelli Universidade Federal do Tocantins - Brasil Campus de Tocantinópolis - TO Membro do Grupo de Pesquisa sobre Condição e Formação Docente (PRODOC/UFMG) E-mail: locatelli@uft.edu.br

Recebido em: 08 de fevereiro de 2017 Aprovado em: 20 de março de 2017 